\title{
Reply to 00464-009-0844-1: Endoscopic submucosal dissection: can indications for a minimally invasive approach be expanded safely to patients with early gastric cancer?
}

\author{
Hae Yeon Kang • Sang Gyun Kim • \\ Joo Sung Kim • Hyun Chae Jung • In Sung Song
}

Published online: 28 January 2010

(C) Springer Science+Business Media, LLC 2010

We thank Dr. Fatourou and Roukos for their interest and remarks in response to our article regarding endoscopic resection for undifferentiated early gastric cancer [1].

Since 1999, a national cancer screening program has recommended upper gastrointestinal endoscopy to the normal population older than 40 years for early detection of gastric cancer in Korea. The proportion of early gastric cancer indicated for endoscopic resection has increased. Although conventional endoscopic resection was limited to complete resection only for large or deep tumors confined to the mucosa without the risk of lymph node metastasis, newly developed endoscopic submucosal dissection has enabled complete resection of larger and deeper tumor without any technical barrier.

With the progress of technical advances, Japan has proposed expanding the indications for endoscopic resection of early gastric cancer [2]. Although tumor of undifferentiated histology has the risk of much larger size and deeper invasion than expected, some portion of an early lesion could possibility be indicated for complete endoscopic resection as a minimally invasive treatment.

In a retrospective study with postoperative pathologic review, undifferentiated early gastric cancer smaller than $2.5 \mathrm{~cm}$ and confined to the mucosa did not show any lymph node metastasis in a large series [3]. As expected, the complete resection rate for undifferentiated early gastric cancer was significantly lower than for differentiated histology, which explains the possibility of diffuse infiltration of tumor with undifferentiated histology and the risk of lymph node metastasis.

Although endoscopic submucosal dissection has improved the complete resection of early gastric cancer more than conventional mucosal resection, expanding the indication to tumor of undifferentiated histology has the risk of incomplete resection or lymph node metastasis and should be accompanied by long-term follow-up evaluation. We think the indication for endoscopic resection of undifferentiated gastric cancer should be limited to small tumors confined to the mucosa.

Disclosures Hae Yeon Kang, Sang Gyun Kim, Joo Sung Kim, Hyun Chae Jung, and In Sung Song have no conflicts of interest or financial ties to disclose.

\section{References}

1. Kang HY, Kim SG, Kim JS, Jung HC, Song IS (2009) Clinical outcomes of endoscopic submucosal dissection for undifferentiated early gastric cancer. Sug Endosc. doi:10.1007/s00464-0090844-1

2. Soetikno R, Kaltenbach T, Yeh R, Gotoda T (2005) Endoscopic mucosal resection for early cancers of the upper gastrointestinal tract. J Clin Oncol 23:4490-4498

3. Ye BD, Kim SG, Lee JY, Kim JS, Yang HK, Kim WH, Jung HC, Lee KU, Song IS (2008) Predictive factors for lymph node metastasis and endoscopic treatment strategies for undifferentiated early gastric cancer. J Gastroenterol Hepatol 23:46-50
H. Y. Kang · S. G. Kim $(\bowtie) \cdot$ J. S. Kim ·

H. C. Jung · I. S. Song

Department of Internal Medicine and Liver Research Institute, Seoul National University College of Medicine, Seoul, Korea e-mail: harley1333@hanmail.net 